\title{
Testing the asymmetric causal nexus of housing-oil prices and pandemic uncertainty in four major economies
}

\author{
Andrew Adewale Alola ${ }^{1,2} \cdot$ Gizem Uzuner $^{1}$ (D) \\ Received: 9 March 2021 / Accepted: 15 June 2021 / Published online: 22 June 2021 \\ (C) The Author(s), under exclusive licence to Springer-Verlag GmbH Germany, part of Springer Nature 2021
}

\begin{abstract}
The spread of COVID-19 worldwide has shown how quick global economy can become affected when ones' health and future are at risk. This paper examines the evidence of Granger causality among the housing price, the unemployment rate, crude oil price, and world pandemic uncertainty in France, Germany, the UK, and the USA over the period 1996Q1-2019Q2. In this case, the linear and asymmetric Granger causality approaches of Toda-Yamamoto and Hatemi-J are respectively applied to provide useful insight. Although only significant evidence of linear Granger causality is found among the unemployment rate and the house prices in all the four economies, the investigations revealed asymmetric evidence involving the world pandemic uncertainty. Specifically, there is a significant uni-directional asymmetric Granger causality from the world pandemic uncertainty to the house price in France, Germany, and the USA but not in the UK. The variation in the results among the examined countries is explained by potential differences in economic structures or business cycle and other social and economic factors. Thus, relevant policy guidance is implied from the results especially for the policymakers in the examined countries.
\end{abstract}

Keywords Pandemics $\cdot$ Housing market $\cdot$ Crude oil price $\cdot$ Unemployment rate $\cdot$ Major economies

JEL classification $\mathrm{E} 24 \cdot \mathrm{I} 10 \cdot \mathrm{R} 31 \cdot \mathrm{Q} 41$

\section{Introduction}

From human history, a handful of pandemic and epidemics of public health emergencies such as the severe acute respiratory syndrome (SARS), cholera, and influenza diseases have been associated with millions of human causalities (World Health Organization: WHO 2020). In specific, five major influenza pandemics have reportedly bewildered and caused severely varying consequences across the globe (Centre for Diseases Control and Prevention: CDC 2018). So far, the 1918 pandemic of the H1N1 viral origin and widely regarded as the

Responsible Editor: Philippe Garrigues

Gizem Uzuner

guzuner@gelisim.edu.tr

Andrew Adewale Alola

aadewale@gelisim.edu.tr

1 Faculty of Economics, Administrative and Administrative and Social Sciences, Istanbul Gelisim University, Istanbul, Turkey

2 Department of Economics and Finance, South Ural State University, Chelyabinsk, Russia
"Spanish flu" has remained the most devastating of a pandemic in history (CDC 2018; WHO 2020). Thereafter, the 19571958 Pandemic (also known as H2N2 or "Asian Flu"), the 1968 pandemic (also known as H3N2), and the $2009 \mathrm{H} 1 \mathrm{~N} 1$ Pandemic (CDC 2018) have all-cause varying degree of health, socio-economic, and several devastations before the current novel coronavirus (nCOVID-19) pandemic. Similar to the previous pandemics, the nCOVID-19 pandemic has ignited both similar and different measures from all the affected countries but the impact has caused economic tumors. With about 6.5 million infections and more than 380,000 deaths recorded globally (Johns Hopkins University and Medicine 2020), the economic impact of the nCOVID-19 pandemic has since shattered the once optimistic economic forecast of 2020.

In specific, the seemingly necessary measures that are being adopted to combat the spread of the virulent disease (such as the travel restriction or suspension across countries borders, "social distancing," and "lockdown") have since increased economic uncertainty and further threatening the global financial stability. Since the outbreak of the nCOVID-19 pandemic, the International Monetary Fund (IMF 2020) has noted a 
significant decline in prices of risk assets, a record crude oil price decline, and other market strains. Also, Jelilov et al. (2020) in a study on the nexus between stock market returns and inflation with nCovid-19 pandemic for Nigeria, established that the negative effects of COVID-19 on the market returns and its disruption to the stock market returnsinflation relationship may not die away rapidly considering that the duration of the pandemic is unknown. Recent study has illustrated the development and quantification of a significantly huge economic uncertainty due to the nCOVID-19 pandemic and the resulting macroeconomic impact of the pandemic (Baker et al. 2020). Yet, on the connectedness of pandemic-induced uncertainty, Zhang et al. (2020) found significant evidence that the COVID-19 pandemic affects the financial market with significant evidence of volatility (due to the pandemic) across global markets. Reflecting on the current situation, existing evidence has shown that the moment of uncertainty and high risk in the global markets is significantly characterized by the unemployment debacle (Caggiano et al. 2017; Schaal 2017; Usman and Elsalih 2018). Moreover, considering the significance of the energy and the real estate market to the world economy, previous studies have also established the nexus of energy market and economic growth (Sharif et al. 2020; Adedoyin and Bekun 2020; Adedoyin et al. 2021c, d), economic uncertainty and energy market (Balcilar et al. 2017; Balcilar et al. 2020; Uzuner et al. 2021; Adedoyin et al. 2021a, b), and economic uncertainty and the housing market (Antonakakis et al. 2015; Christidou and Fountas 2017; Christou et al. 2017; Alola and Uzuner 2020).

The impact of the pandemic has taken a severe toll on the advanced economies considering the high human causalities recorded in some of these economies. For instance, not until the outbreak of the pandemic, the economic outlook for at least the world's 10 largest economies by nominal gross domestic product (nGDP) was largely optimistic even as in January 2020 (NASDAQ 2020). But, the event of the second quarter of 2020 has presented a skyrocketed job losses, economic shutdown, and increasing uncertainty among the four (France, Germany, UK, and the USA) of the seven world largest economy by nGDP. For instance, yet on record is the almost $15 \%$ national unemployment rate in the USA with first quarter's 5\% decline in GDP and the over 30 million job losses in Europe (mostly in France, Germany, Italy, Spain, and UK) with a projected $8-12 \%$ decline in GDP in 2020 (Congressional Research Service (CRS 2020)). This, by no way, has not undermined other social and economic impacts of COVID-19 pandemic through varying sectors (International Labour Organization 2020). Intuitively, there can be many channels underlying the relationship between house and world pandemic uncertainty: (i) world pandemic uncertainty hikes adversely affect economic growth and, thus, dampen the demand for housing, and along with it reducing its price; (ii) however, uncertainty can increase the cost of investment reversal, so firms reduce residential investment and suspend their projects as they accumulate new information which increase the housing price. Therefore, to understand the linkages between world pandemic uncertainty and the housing price is highly informative for prospective homeowners, economic planners, financial institutions, policymakers, and property investors.

Considering the severity of the nCOVID-19 pandemic in France, Germany, the UK, and the USA (the four of the seven largest economies by GDP), the current study is aimed to investigate the associated uncertainty through outlined perspectives. Importantly, the degree of uncertainty in relation to the pandemic in the four aforementioned economies is being examined within the concept of world pandemic uncertainty $^{1}$ (WPU). Another perspective is to examine the potential (Granger causality) relationship between the pandemicinduced uncertainty with unemployment crisis, oil price, and the housing price in the four major economies. By reflecting on the current unemployment and crude oil crises due to the nCOVID-19 pandemic, the economic intuition behind the consideration of the house price in the current investigation is related to the co-existence of the USA's housing market and the 2007-2008 global financial crisis (Encyclopedia Britannica 2019). As such, the current study is expected to achieve a novel outcome since employing the aforementioned outline is largely assumed the first in the literature by the authors. Moreover, the approach adopted in the study (the Toda-Yamamoto Granger causality and asymmetric causality tests) is expected to provide a significant and country-specific policy to the examined countries and at the same time contribute significantly to the extant literature.

Besides, the other part of the study is outlined accordingly: "Data and methodology" and "Empirical results" provide the empirical method and the discussion of the results respectively. The conclusion and the implied policy are both outlined in "Conclusion and policy implications."

\section{Data and methodology}

\section{Data}

The data used to analyze the dynamic Granger causality relationship between the housing price index (HP), Brent crude oil price (OIL), unemployment (UNEMP), and the world pandemic uncertainty index (WPU) for the four major countries: France, Germany, the UK, and the USA. The current study uses quarterly data over the period 1996Q1 and 2019Q2. Seasonally adjusted data on the HP and UNEMP data are

\footnotetext{
${ }^{1}$ Further information on WPU is available at https://worlduncertaintyindex. com/.
} 
obtained from the OECD database. ${ }^{2}$ The Brent crude oil data is sourced from the FRED database. ${ }^{3}$ The study used the WPU index, which is the "newly developed index on uncertainty," which is proposed by Ahir et al. (2018). The WPU data is obtained from the website https://worlduncertaintyindex. com/data/. The WPU measures economic uncertainty related to pandemics and other disease outbreaks across the world as reflected in the Economist Intelligence Unit country reports.

\section{Asymmetric causality tests}

Conventional Granger causality tests and the TodaYamamoto Granger causality test are also used to investigate the Granger causal direction between the variables. However, these tests cannot separate the impact of positive and negative shocks of the variables on other variables. For this reason, Hatemi-J (2012) proposes the asymmetric causality test that examines the asymmetric direction of the causal relationship between the variables. This test uses the approach of Toda and Yamamoto (1995) and hence splits the positive and negative shocks on the variables. According to Hatemi-J (2012) asymmetric Granger causality test, the integrated variables can be presented as a random walk process as follows:

$$
\begin{aligned}
\mathrm{x}_{1 \mathrm{t}} & =\mathrm{x}_{1 \mathrm{t}-1}+\varepsilon_{1 \mathrm{t}}=\mathrm{x}_{10}+\sum_{\mathrm{i}=1}^{\mathrm{t}} \varepsilon_{1 \mathrm{i}} \text { and } \mathrm{x}_{2 \mathrm{t}}=\mathrm{x}_{2 \mathrm{t}-1}+\varepsilon_{2 \mathrm{t}} \\
& =\mathrm{x}_{20}+\sum_{\mathrm{i}=1}^{\mathrm{t}} \varepsilon_{2 \mathrm{i}}
\end{aligned}
$$

where $\mathrm{t}=1,2, \ldots \mathrm{T}, \mathrm{x}_{10}$ and $\mathrm{x}_{20}$ are initial values, and $\varepsilon_{1 \mathrm{t}}$ and $\varepsilon_{2 \mathrm{t}}$ are the white noise disturbance terms. The positive and negative shocks in the variables are identified by using the following formulations: $\varepsilon_{1 \mathrm{i}}{ }^{+}=\max \left(\varepsilon_{1 \mathrm{i}}, 0\right), \varepsilon_{2 \mathrm{i}}{ }^{+}=\max \left(\varepsilon_{2 \mathrm{i}}, 0\right)$ and $\varepsilon_{1 \mathrm{i}}{ }^{-}=\min \left(\varepsilon_{1 \mathrm{i}}, 0\right), \varepsilon_{2 \mathrm{i}}{ }^{-}=\min \left(\varepsilon_{2 \mathrm{i}}, 0\right)$. Within the framework of directional asymmetry, it follows that $\mathrm{x}_{1 \mathrm{t}}=\mathrm{x}_{1 \mathrm{t}-1}+\varepsilon_{1 \mathrm{t}}=\mathrm{x}_{10}$ $+\sum_{\mathrm{i}=1}^{\mathrm{t}} \varepsilon_{1 \mathrm{i}}{ }^{+}+\sum_{\mathrm{i}=1}^{\mathrm{t}} \varepsilon_{1 \mathrm{i}}{ }^{-}$and $\mathrm{x}_{2 \mathrm{t}}=\mathrm{x}_{2 \mathrm{t}-1}+\varepsilon_{2 \mathrm{t}}=\mathrm{x}_{20}+\sum_{\mathrm{i}=1}^{\mathrm{t}} \varepsilon_{2 \mathrm{i}}{ }^{+}+$ $\sum_{\mathrm{i}=1}^{\mathrm{t}} \varepsilon_{2 \mathrm{i}}{ }^{-}$. The positive and negative shocks to all variables in this study can be expressed in the cumulative forms as follows: $\mathrm{x}_{1 \mathrm{t}}{ }^{+}=\sum_{\mathrm{i}=1}^{\mathrm{t}} \varepsilon_{1 \mathrm{i}}{ }^{+}, \mathrm{x}_{1 \mathrm{t}}{ }^{-}=\sum_{\mathrm{i}=1}^{\mathrm{t}} \varepsilon_{1 \mathrm{i}}{ }^{-}$and $\mathrm{x}_{2 \mathrm{t}}{ }^{+}=\sum_{\mathrm{i}=1=1}^{\mathrm{t}} \varepsilon_{2 \mathrm{i}}{ }^{+}, \mathrm{x}_{2 \mathrm{t}}{ }^{-}$ $=\sum_{\mathrm{i}=1}^{\mathrm{t}} \varepsilon_{2 \mathrm{i}}{ }^{-}$. More specifically, these cumulative forms can be used to investigate the asymmetric causal relationship between the variables through a vector autoregressive model of order $p, \operatorname{VAR}(p)$. In order to determine the optimal lag order in this model, this study used Hatemi-J Criterion (HJC) which is calculated as follows:

$$
\mathrm{HJC}=\ln (\operatorname{det} \widehat{\Omega} \mathrm{j})+\mathrm{j}\left(\frac{n^{2} \ln \mathrm{T}+2 n^{2} \ln (\ln \mathrm{T})}{2 \mathrm{~T}}\right) \quad \mathrm{j}=0,1, \ldots, p
$$

\footnotetext{
${ }^{2}$ Access date: June 2020

${ }^{3}$ Access date: June 2020
}

where $\widehat{\Omega}_{\mathrm{j}}$ denotes the variance-covariance matrix estimator which is obtained from the error term in the VAR model with lag order $j$, whereas $T$ refers to the number of observations and $n$ represents the number of equations in the VAR model. The null hypothesis of non-causality can be tested using a modified version of the Wald statistic. ${ }^{4}$

\section{Empirical results}

Table 1 exhibits the descriptive statistics on all variables used in our analysis. Firstly, the descriptive statistics focus on the Brent crude oil price and the world pandemic uncertainty which are common for four major countries. According to Table 1, oil price volatility is higher than world pandemic uncertainty. Housing price index volatility is the highest in the UK while the lowest in Germany. Also, the volatility of unemployment is almost the same for the countries. Moreover, most of the variables are right-skewed with positive kurtosis value which indicates non-normal distribution. Besides that, the null hypothesis of non-normal distribution is rejected by using the Jarque-Bera statistics for all variables

The Wald test result has a non-standard distribution if the variables in a VAR model are integrated or cointegrated. Thus, the conventional Granger causality approach in the linear framework is needed to test for unit root and cointegration relation. However, the Toda-Yamamoto Granger causality method overcomes the long-run information loss by estimating the VAR $\left(k+d_{\max }\right)$ model with level data, using the level values of the data. $d_{\max }$ is the maximum integrated order of the variables $^{5}$ and $k$ is the optimal lag length. The VAR $\left(k+d_{\max }\right)$ is constructed as:

$$
\begin{aligned}
H P_{t}= & \beta_{0}+\sum_{i=1}^{k} \beta_{1 i} H P_{t-i}+\sum_{j=k+1}^{d_{\max }} \beta_{2 j} H P_{t-i} \\
& +\sum_{i=1}^{k} \vartheta_{1 i} W P U_{t-i}+\sum_{j=k+1}^{d_{\max }} \vartheta_{2 j} W P U_{t-i} \\
& +\sum_{i=1}^{k} \delta_{1 i} U N E M P_{t-i}+\sum_{j=k+1}^{d_{\max }} \delta_{2 j} U_{N E M P_{t-i}}+\varepsilon_{t}(3)
\end{aligned}
$$

Thus, the Toda-Yamamoto Granger causality test is used to determine the direction of causality between the variables. In Table 2, the results of Toda-Yamamoto Granger causality show that there is no Granger causality relationship running from world pandemic uncertainty to housing price for four major countries. However, there is a unidirectional Granger causality from unemployment to housing prices for France. Also, the findings revealed that there is a unidirectional Granger causality relationship from oil price to housing price for the USA.

\footnotetext{
${ }^{4}$ For detailed information, interested readers should see Hatemi-J (2012).

${ }^{5}$ In this study, the $d$ is 1 based on the results of augmented Dickey-Fuller and Zivot-Andrews unit root tests. For brevity, we removed the unit root tests which can be available upon request.
} 
Table 1 Descriptive statistics

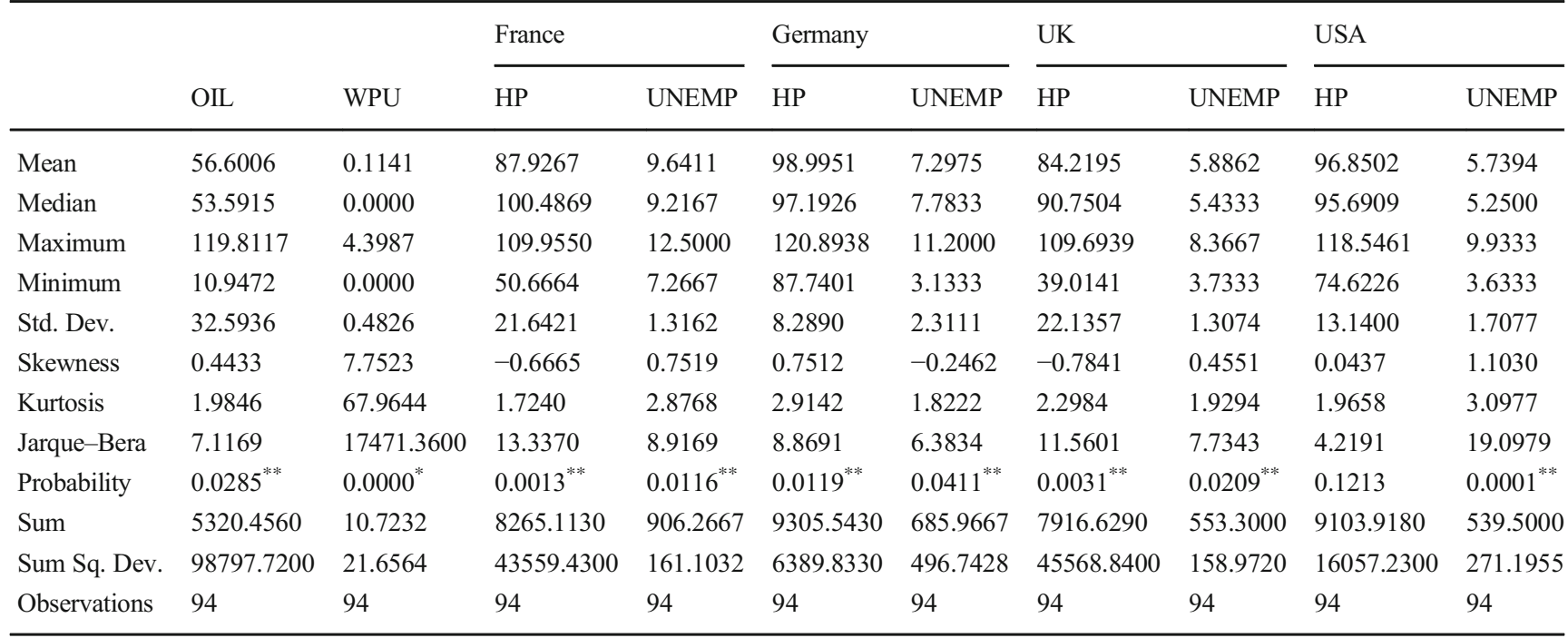

Note: The asterisks ${ }^{*}$ and ${ }^{* * *}$ indicate the rejection of the null hypothesis at 0.01 and 0.10 significance level

The BDS non-linearity test is used to check the robustness of the Toda-Yamamoto Granger causality test. Table 3 presents the BDS test results. The findings show the nonlinearity in the aforementioned variables. In this case, the use of Granger causality tests in the linear framework causes misspecification problems. Hence, the Hatemi-J (2012)

Table 2 Toda-Yamamoto Granger causality test results

\begin{tabular}{llll}
\hline Hypothesis & Chi-square & P-value & Decision \\
\hline France & & & \\
OIL $\neq>$ HP & 3.364 & 0.186 & OIL $\neq>$ HP \\
WPU $\neq>$ HP & 0.734 & 0.693 & WPU $\neq>$ HP \\
UNEMP $\neq>$ HP & $13.424^{*}$ & 0.001 & UNEMP $\rightarrow$ HP \\
Germany & & & \\
OIL $\neq>$ HP & 0.595 & 0.743 & OIL $\neq>$ HP \\
WPU $\neq>$ HP & 0.125 & 0.939 & WPU $\neq>$ HP \\
UNEMP $\neq>$ HP & 0.643 & 0.725 & UNEMP $\neq>$ HP \\
UK & & & \\
OIL $\neq>$ HP & $5.522^{* *}$ & 0.011 & OIL $\rightarrow$ HP \\
WPU $\neq>$ HP & 1.032 & 0.312 & WPU $\neq>$ HP \\
UNEMP $\neq>$ HP & $14.463^{* *}$ & 0.029 & UNEMP $\rightarrow$ HP \\
USA & & & \\
OIL $\neq>$ HP & $22.666^{*}$ & 0.000 & OIL $\rightarrow$ HP \\
WPU $\neq>$ HP & 3.071 & 0.215 & WPU $\neq>$ HP \\
UNEMP $\neq>$ HP & 3.437 & 0.179 & UNEMP $\neq>$ HP \\
\hline
\end{tabular}

Note: The symbols " $\neq>$ and $\rightarrow$ " denote the non-Granger causality and unidirectional Granger causality relationship for the selected variables. The superscripts ${ }^{* *}$ and ${ }^{* * *}$ indicate the 0.05 and 0.10 significance level. The optimal lag is selected as 2 by using SIC asymmetric causality test technique is applied to consider the nonlinearity relationship between variables.

Table 4 presents the asymmetric Granger causality test results for France. The findings indicate that a positive shock of world pandemic uncertainty Granger causes a negative shock

Table 3 BDS non-linearity tests

\begin{tabular}{llll}
\hline Variables & BDS statistic & Standard error & Probability \\
\hline France & & & \\
HP & $0.205^{*}$ & 0.006 & 0.000 \\
OIL & $0.165^{*}$ & 0.005 & 0.000 \\
WPU & $0.068^{*}$ & 0.017 & 0.000 \\
UNEMP & $0.192^{*}$ & 0.009 & 0.000 \\
Germany & & & \\
HP & $0.176^{*}$ & 0.007 & 0.000 \\
OIL & $0.165^{*}$ & 0.005 & 0.000 \\
WPU & $0.068^{*}$ & 0.017 & 0.000 \\
UNEMP & $0.188^{*}$ & 0.005 & 0.000 \\
UK & & & 0.000 \\
HP & $0.208^{*}$ & 0.007 & 0.000 \\
OIL & $0.165^{*}$ & 0.005 & 0.000 \\
WPU & $0.068^{*}$ & 0.017 & 0.000 \\
UNEMP & $0.186^{*}$ & 0.006 & 0.000 \\
USA & & & 0.000 \\
HP & $0.190^{*}$ & 0.004 & 0.000 \\
OIL & $0.165^{*}$ & 0.005 & 0.000 \\
WPU & $0.068^{*}$ & 0.017 & 0.009 \\
UNEMP & $0.188^{*}$ & & \\
\hline
\end{tabular}

Note: ${ }^{*}$ indicates the rejection of the null hypothesis at 0.01 significance level. The number of dimensions is 2 
Table 4 Asymmetric causality test for France

\begin{tabular}{llll}
\hline Hypothesis & Fisher statistic & P-value & Decision \\
\hline OIL $^{+} \neq>H P^{+}$ & 4.331 & 0.115 & OIL $^{+} \neq>H P^{+}$ \\
$\mathrm{OIL}^{+} \neq>H P^{-}$ & $4.791^{* * * *}$ & 0.091 & $\mathrm{OIL}^{+} \rightarrow H P^{-}$ \\
$\mathrm{OIL}^{-} \neq>H P^{-}$ & 0.652 & 0.722 & $\mathrm{OIL}^{-} \neq>H P^{-}$ \\
$\mathrm{OIL}^{-} \neq>H P^{+}$ & $5.816^{* * * *}$ & 0.055 & $\mathrm{OIL}^{-} \rightarrow H P^{+}$ \\
$W P U^{+} \neq>H P^{+}$ & 0.578 & 0.749 & $W P U^{+} \neq>H P^{+}$ \\
$W P U^{+} \neq>H P^{-}$ & $7.182^{* *}$ & 0.028 & $W P U^{+} \rightarrow H P^{-}$ \\
$W P U^{-} \neq>H P^{-}$ & 0.169 & 0.919 & $W P U^{-} \neq>H P^{-}$ \\
$W P U^{-} \neq>H P^{+}$ & 4.466 & 0.107 & $W P U^{-} \neq>H P^{+}$ \\
$U N E M P^{+} \neq>H P^{+}$ & 1.409 & 0.494 & $U N E M P^{+} \neq>H P^{+}$ \\
$U N E M P^{+} \neq>H P^{-}$ & 0.242 & 0.886 & $U N E M P^{+} \neq>H P^{-}$ \\
$U N E M P^{-} \neq>H P^{-}$ & 0.385 & 0.825 & $U N E M P^{-} \neq>H P^{-}$ \\
$U N E M P^{-} \neq>H P^{+}$ & 0.898 & 0.638 & $U N E M P^{-} \neq>H P^{+}$ \\
\hline
\end{tabular}

Note: The symbols " $\neq>$ " and " $\rightarrow$ " denote the non-Granger causality and unidirectional Granger causality relationship for the selected variables. The superscripts ${ }^{* *}$ and ${ }^{* * *}$ indicate the 0.05 and 0.10 significance level. The optimal lag is selected based on Hatemi-J Criterion (HJC)

of the housing price index. It means that a positive shock of the world pandemic uncertainty is a good predictor to forecast a negative shock of the housing price index. This is expected because of the law of demand theory arising from low housing demand during pandemics expectedly causing low housing prices. Additionally, there is an asymmetric Granger causality relationship from a positive shock of oil price to a negative shock of the housing price index. These outcomes support the expectation of IMF (2020). However, the results show that there is no existing asymmetric Granger causality relationship between the housing price index and unemployment. This finding aligns with Pan (2018) for the G7 countries while it is not aligned with Alola (2020) for Cyprus.

Table 5 reports the asymmetric Granger causality test for Germany. Similarly, to the results of France, a positive shock of the world pandemic uncertainty Granger causes a negative shock of the housing price index. Expectedly, the aforementioned law of demand theory ascribed to the case of France is also relevant for the case of Germany. Moreover, there is a unidirectional Granger causality running from a negative shock of oil price to a negative shock of the housing price index. Additionally, a positive shock of unemployment Granger causes a negative shock of the housing price index. However, the finding did not reveal the feedback relationship between unemployment and housing price index in contrast to the study of Irandoust (2019) for Germany. We conclude that positive shocks of world pandemic uncertainty and declines in oil price and unemployment have a significant predictive power for decreases in the housing price index in Germany.

In Table 6, the results of the asymmetric Granger causality test show that none of the shocks of the variables Granger
Table 5 Asymmetric causality test for Germany

\begin{tabular}{llll}
\hline Hypothesis & Fisher statistic & P-value & Decision \\
\hline OIL $^{+} \neq>H P^{+}$ & 2.409 & 0.300 & $\mathrm{OIL}^{+} \neq>H P^{+}$ \\
$\mathrm{OIL}^{+} \neq>H P^{-}$ & 1.763 & 0.414 & $\mathrm{OIL}^{+} \neq>H P^{-}$ \\
$\mathrm{OIL}^{-} \neq>H P^{-}$ & $12.979^{*}$ & 0.002 & $\mathrm{OIL}^{-} \rightarrow H P^{-}$ \\
$\mathrm{OIL}^{-} \neq>H P^{+}$ & 0.657 & 0.720 & $\mathrm{OIL}^{-} \neq>H P^{+}$ \\
$W P U^{+} \neq>H P^{+}$ & 1.193 & 0.551 & $W P U^{+} \neq>H P^{+}$ \\
$W P U^{+} \neq>H P^{-}$ & $10.592^{*}$ & 0.005 & $W P U^{+} \rightarrow H P^{-}$ \\
$W P U^{-} \neq>H P^{-}$ & 0.429 & 0.807 & $W P U^{-} \neq>H P^{-}$ \\
$W P U^{-} \neq>H P^{+}$ & 0.844 & 0.656 & $W P U^{-} \neq>H P^{+}$ \\
$U N E M P^{+} \neq>H P^{+}$ & 3.977 & 0.137 & $U N E M P^{+} \neq>H P^{+}$ \\
$U N E M P^{+} \neq>H P^{-}$ & $12.088^{*}$ & 0.002 & $U N E M P^{+} \rightarrow H P^{-}$ \\
$U N E M P^{-} \neq>H P^{-}$ & 1.012 & 0.603 & $U N E M P^{-} \neq>H P^{-}$ \\
$U N E M P^{-} \neq>H P^{+}$ & 2.542 & 0.281 & $U N E M P^{-} \neq>H P^{+}$ \\
\hline
\end{tabular}

Note: The symbols " $\neq>$ " and " $\rightarrow$ " denote the non-Granger causality and unidirectional Granger causality relationship for the selected variables. The superscript ${ }^{*}$ presents the 0.01 significance level. The optimal lag is selected as 3 by using Hatemi-J Criterion (HJC)

causes the housing price index in the UK. The result of Granger non-causality relation from unemployment to the housing price index is supported by Sibande et al. (2019) for the UK. It can be concluded that the world pandemic uncertainty, oil price, and unemployment are not helpful to forecast the UK housing price index. The lack of Granger causality evidence from the aforementioned variables to housing price could be associated with the strong fiscal and monetary policy from the aftermath of the last global financial crisis.

Lastly, Table 7 presents the asymmetric Granger causality test results for the USA. The findings indicate that there is a

Table 6 Asymmetric causality test for the UK

\begin{tabular}{llll}
\hline Hypothesis & Fisher statistic & P-value & \\
\hline OIL $^{+} \neq>H P^{+}$ & 2.394 & 0.302 & OIL $^{+} \neq>H P^{+}$ \\
OIL $^{+} \neq>H P^{-}$ & 1.882 & 0.390 & OIL $^{+} \neq>H P^{-}$ \\
OIL $^{-} \neq>H P^{-}$ & 0.302 & 0.860 & OIL $^{-} \neq>H P^{-}$ \\
OIL $^{-} \neq>H P^{+}$ & 0.609 & 0.737 & OIL $^{-} \neq>H P^{+}$ \\
$W P U^{+} \neq>H P^{+}$ & 2.303 & 0.316 & $W P U^{+} \neq>H P^{+}$ \\
$W P U^{+} \neq>H P^{-}$ & 4.023 & 0.134 & $W P U^{+} \neq>H P^{-}$ \\
$W P U^{-} \neq>H P^{-}$ & 0.081 & 0.960 & $W P U^{-} \neq>H P^{-}$ \\
$W P U^{-} \neq>H P^{+}$ & 1.411 & 0.494 & $W P U^{-} \neq>H P^{+}$ \\
$U N E M P^{+} \neq>H P^{+}$ & 1.163 & 0.559 & $U N E M P^{+} \neq>H P^{+}$ \\
$U N E M P^{+} \neq>H P^{-}$ & 2.317 & 0.314 & $U N E M P^{+} \neq>H P^{-}$ \\
$U N E M P^{-} \neq>H P^{-}$ & 1.289 & 0.525 & $U N E M P^{-} \neq>H P^{-}$ \\
$U N E M P^{-} \neq>H P^{+}$ & 1.93 & 0.381 & $U N E M P^{-} \neq>H P^{+}$ \\
\hline
\end{tabular}

Note: The symbol " $\neq>$ " denotes the non-Granger causality relationship for the selected variables. The optimal lag is selected based on using Hatemi-J Criterion (HJC) 
unidirectional Granger causality running from a negative shock of the world pandemic uncertainty to a positive shock of housing price. This finding is also supported by Francke and Korevaar (2021). The determination cum desperation of the property or house owners to cover their market loss due to the pandemics could trigger the unexpected hike in housing prices during the recovery period of the economy. Also, there is an asymmetric Granger causality relationship from a negative shock of unemployment to a positive shock of the housing price index. The result is resonated with the study of BahmaniOskooee and Ghodsi (2016) for the US states.

\section{Conclusion and policy implications}

The vulnerability of the global market to shock has persistently remained a long time challenge to economic growth and sustainable development. Regarding the essential commodity markets such as the energy and the housing markets, evidence has continued to show the vulnerability of these markets to the economic downturn. As such, like the pandemics in human history, the uncertainty resulting from the current nCOVID-19 pandemic has caused a significant record decline in crude oil prices, thus leading to significant global market strains. In an attempt to understand the potential effect of pandemic uncertainty, the current study affirmed a Granger causality evidence from the housing market, energy market, and unemployment rate especially in the world's most affected and largest economies (France, Germany, UK, and the USA). Interestingly, the Toda-Yamamoto approach revealed a uni-directional linear Granger causality from unemployment to house prices for

Table 7 Asymmetric causality test for the USA

\begin{tabular}{lcll}
\hline Hypothesis & Fisher statistic & P-value & Decision \\
\hline $\mathrm{OIL}^{+} \neq>H P^{+}$ & 0.365 & 0.833 & $\mathrm{OIL}^{+} \neq>H P^{+}$ \\
$\mathrm{OIL}^{+} \neq>H P^{-}$ & 1.918 & 0.383 & $\mathrm{OIL}^{+} \neq>H P^{-}$ \\
$\mathrm{OIL}^{-} \neq>H P^{-}$ & 4.217 & 0.121 & $\mathrm{OIL}^{-} \neq>H P^{-}$ \\
$\mathrm{OIL}^{-} \neq>H P^{+}$ & 2.157 & 0.340 & $\mathrm{OIL}^{-} \neq>H P^{+}$ \\
$W P U^{+} \neq>H P^{+}$ & 0.291 & 0.864 & $W P U^{+} \neq>H P^{+}$ \\
$W P U^{+} \neq>H P^{-}$ & 2.567 & 0.277 & $W P U^{+} \neq>H P^{-}$ \\
$W P U^{-} \neq>H P^{-}$ & 0.009 & 0.996 & $W P U^{-} \neq>H P^{-}$ \\
$W P U^{-} \neq>H P^{+}$ & $4.919^{* * *}$ & 0.085 & $W P U^{-} \rightarrow H P^{+}$ \\
$U N E M P^{+} \neq>P^{+}$ & 0.195 & 0.907 & $U N E M P^{+} \neq>H P^{+}$ \\
$U N E M P^{+} \neq>H P^{-}$ & 0.721 & 0.697 & $U N E M P^{+} \neq>H P^{-}$ \\
$U N E M P^{-} \neq>H P^{-}$ & 0.404 & 0.817 & $U N E M P^{-} \neq>H P^{-}$ \\
$U N E M P^{-} \neq>H P^{+}$ & $19.424^{*}$ & 0.000 & $U N E M P^{-} \rightarrow H P^{+}$ \\
\hline
\end{tabular}

Note: The symbols " $\neq>$ " and " $\rightarrow$ " denote the non-Granger causality and unidirectional Granger causality relationship for the selected variables. The superscripts ${ }^{*}$ and ${ }^{* * *}$ indicate the 0.01 and 0.10 significance level. The optimal lag is selected based on Hatemi-J Criterion (HJC)
France and the UK but the reverse is only true for Germany and the USA. Moreover, the asymmetric causality evidence by Hatemi-J (2012) further provided insightful information. In specific, Hatemi-J (2012) revealed a significant Granger causality from world pandemic uncertainty to the housing market vis-à-vis house in France, Germany, and the USA. Similar to the aforementioned linear Granger causality evidence, the asymmetry Granger evidence further posited a unidirectional Granger causality from unemployment rate and oil price to house price only in Germany and the USA.

One of the importance of this study is the policy measure it potentially offers to the government of France, Germany, the UK, and the USA. Among the potential policy, the directive is that the governments of France, Germany, and the USA could further re-invigorate the housing market such as providing interest rate adjustment that favors the real estate investors. Since there seems to be a Granger causality between the unemployment rate, house, and the crude oil price, the governments of the examined countries should strengthen publicprivate partnerships in terms of job security policy especially in the current circumstance of nCOVID-19 pandemic.

Acknowledgments Author gratitude is extended to the prospective editor(s) and reviewers that will/have spared time to guide toward a successful publication.

Availability of data and materials The data for this present study are sourced from the OECD database https://data.oecd.org/. The Brent crude oil data is sourced from the FRED database https://fred.stlouisfed.org/. The WPU data is obtained from the website: https:// worlduncertaintyindex.com/data/. The current specific data can be made available upon request but all available and downloadable at the earlier mentioned database and weblink.

Author contribution AA carried out the study and participated in the sequence supervision, conceptualization, and writing — original draft and editing. GU participated in the design methodology and performed the statistical analysis and writing - original draft. Both authors read and approved the final manuscript.

\section{Declarations}

Consent to participate Not applicable

Consent to publish The authors have given consent for submission and subsequent publication of the manuscript.

Competing interests The authors declare no competing interests.

\section{References}

Adedoyin FF, Bekun FV (2020) Modelling the interaction between tourism, energy consumption, pollutant emissions and urbanization: renewed evidence from panel VAR. Environ Sci Pollut Res 27(31):38881-38900 
Adedoyin FF, Nwulu N, Bekun FV (2021a) Environmental degradation, energy consumption and sustainable development: accounting for the role of economic complexities with evidence from World Bank income clusters. Bus Strateg Environ. https://doi.org/10.1002/bse. 2774

Adedoyin FF, Nathaniel S, Adeleye N (2021b) An investigation into the anthropogenic nexus among consumption of energy, tourism, and economic growth: do economic policy uncertainties matter? Environ Sci Pollut Res 28(3):2835-2847

Adedoyin FF, Alola AA, Bekun FV (2021c) The alternative energy utilization and common regional trade outlook in EU-27: evidence from common correlated effects. Renew Sust Energ Rev 145: 111092

Adedoyin FF, Ozturk I, Agboola MO, Agboola PO, Bekun FV (2021d) The implications of renewable and non-renewable energy generating in Sub-Saharan Africa: The role of economic policy uncertainties. Energy Policy 150:112115

Ahir H, Bloom N, Furceri D (2018) The world uncertainty index. Available at SSRN 3275033

Alola AA (2020) Revisiting the housing market dynamics and its fundamentals: new evidence from Cyprus. J Econ Stud 47(1):200-216

Alola AA, Uzuner G (2020) The housing market and agricultural land dynamics: Appraising with Economic Policy Uncertainty Index. Int J Financ Econ 25(2):274-285

Antonakakis N, Gupta R, Andra C (2015) Dynamic co-movements between economic policy uncertainty and housing market returns. J Real Estate Portf Manag 21(1):53-60

Bahmani-Oskooee M, Ghodsi SH (2016) Do changes in the fundamentals have symmetric or asymmetric effects on house prices? Evidence from 52 states of the United States of America. Appl Econ 48(31): 2912-2936

Baker SR, Bloom N, Davis SJ, Terry SJ (2020) Covid-induced economic uncertainty (No. w26983). National Bureau of Economic Research

Balcilar M, Bekiros S, Gupta R (2017) The role of news-based uncertainty indices in predicting oil markets: a hybrid nonparametric quantile causality method. Empir Econ 53(3):879-889

Balcilar M, Gupta R, Wang S, Wohar ME (2020) Oil price uncertainty and movements in the US government bond risk premia. North Am $\mathrm{J}$ Econ Finance 52:101147

Caggiano G, Castelnuovo E, Figueres JM (2017) Economic policy uncertainty and unemployment in the United States: a nonlinear approach. Econ Lett 151:31-34

Centre for Diseases Control and Prevention: CDC 2018) https://www. cdc.gov/flu/pandemic-resources/basics/past-pandemics.html. (Accessed 01 June 2020).

Christidou M, Fountas S (2017) Uncertainty in the housing market: evidence from US states. Stud Nonlinear Dyn Econ 22(2)

Christou C, Gupta R, Hassapis C (2017) Does economic policy uncertainty forecast real housing returns in a panel of OECD countries? A Bayesian approach. Q Rev Econ Finance 65:50-60

Congressional Research Service (CRS) (2020) Coronavirus disease 2019 (COVID-19). https://crsreports.congress.gov/Content/html/ covid19.html. (Accessed 01 June 2020)

Encyclopedia Britannica (2019) Available from: https://www.britannica. com/event/financial-crisis-of-2007-2008/Key-eventsof-the-crisis. Accessed 25 Dec 2019
Francke M, Korevaar M (2021) Housing markets in a pandemic: evidence from historical outbreaks. J Urban Econ 123:103333

Hatemi-j A (2012) Asymmetric causality tests with an application. Empir Econ 43(1):447-456

International Labour Organization (2020) Sectoral impact, responses and recommendations. https://www.ilo.org/global/topics/coronavirus/ sectoral/lang\%2D\%2Den/index.htm. (Accessed 01 June 2020).

International Monetary Fund, IMF (2020) COVID-19 crisis poses threat to financial stability. https://blogs.imf.org/2020/04/14/covid-19crisis-poses-threat-to-financial-stability/. (Accessed 01 June 2020)

Irandoust M (2019) House prices and unemployment: an empirical analysis of causality. International Journal of Housing Markets and Analysis 12(1):148-164

Jelilov G, Iorember PT, Usman O, Yua PM (2020) Testing the nexus between stock market returns and inflation in Nigeria: Does the effect of COVID-19 pandemic matter? J Public Aff 20(4):e2289

Johns Hopkins University and Medicine (2020) COVID-19 Dashboard by the Center for Systems Science and Engineering (CSSE) at Johns Hopkins University (JHU). https://coronavirus.jhu.edu/map.html. (Accessed 01 June 2020).

NASDAQ (2020). The 5 largest economies in the world and their growth in 2020. https://www.nasdaq.com/articles/the-5-largest-economiesin-the-world-and-their-growth-in-2020-2020-01-22. (Accessed 01 June 2020).

Pan WF (2018) Does the stock market really cause unemployment? A cross-country analysis. North Am J Econ Finance 44:34-43

Schaal E (2017) Uncertainty and unemployment. Econometrica 85(6): $1675-1721$

Sharif A, Baris-Tuzemen O, Uzuner G, Ozturk I, Sinha A (2020) Revisiting the role of renewable and non-renewable energy consumption on Turkey's ecological footprint: Evidence from Quantile ARDL approach. Sustain Cities Soc 57:102138

Sibande X, Gupta R, Wohar ME (2019) Time-varying causal relationship between stock market and unemployment in the United Kingdom: historical evidence from 1855 to 2017. J Multinatl Financ Manag 49:81-88

Toda HY, Yamamoto T (1995) Statistical inference in vector autoregressions with possibly integrated processes. J Econ 66(1-2): $225-250$

Usman O, Elsalih OM (2018) Testing the effects of real exchange rate pass-through to unemployment in Brazil. Economies 6(3):49

Uzuner G, Usman O, Alola AA (2021) An examination of the passthrough of disaggregated energy prices to real house price: evidence from the United States. J Public Aff. https://doi.org/10.1002/pa. 2638

World Health Organization: WHO (2020) https://www.who.int/ emergencies/news/highlights/en/. (Accessed 01 June 2020)

Zhang D, Hu M, Ji Q (2020) Financial markets under the global pandemic of COVID-19. Financ Res Lett 101528

Publisher's note Springer Nature remains neutral with regard to jurisdictional claims in published maps and institutional affiliations. 